\title{
Correction to: An efficient and stabilised SPH method for large strain metal plastic deformations
}

\author{
Giorgio Greto $^{1}$ (D) Sivakumar Kulasegaram ${ }^{1}$ (i)
}

Published online: 9 November 2019

(c) The Author(s) 2019

\section{Correction to: \\ Computational Particle Mechanics https://doi.org/10.1007/s40571-019-00277-6}

The typesetting process incorrectly introduced a " $\nabla$ " symbol inside the "Time-stepping the solution" box at the end of paragraph 4.3, directly under the "Compute first PiolaKirchhoff stress tensor Pi" line. The correct version should read as "Given initial $C(p), J$ and $\epsilon(p)$ ".
The original article has been corrected.

\begin{abstract}
Open Access This article is distributed under the terms of the Creative Commons Attribution 4.0 International License (http://creativecomm ons.org/licenses/by/4.0/), which permits unrestricted use, distribution, and reproduction in any medium, provided you give appropriate credit to the original author(s) and the source, provide a link to the Creative Commons license, and indicate if changes were made.
\end{abstract}

Publisher's Note Springer Nature remains neutral with regard to jurisdictional claims in published maps and institutional affiliations.
The original article can be found online at https://doi.org/10.1007/ s40571-019-00277-6.

\section{Giorgio Greto}

gretog@cardiff.ac.uk

1 School of Engineering, Cardiff University, Queen's Buildings, The Parade, Cardiff CF24 3AA, UK 